\title{
ParalOhde!?
}

\section{O RESGATE DA INVESTIGAÇÃO ONTOLÓGICA NA GEOGRAFIA ATRAVÉS DA FENOMENOLOGIA-HERMENÊUTICA DE MARTIN HEIDEGGER}

\author{
The Rescue Of Ontological Investigation In Geography Through Martin Heidegger's \\ Phenomenology-Hermeneutics
}

Luis Carlos Tosta Dos Reis

Josimar Monteiro Santos**

\begin{abstract}
*Docente do PPG em Geografia da Universidade Federal do Espírito Santo - Ictosta.reis@gmail.com. **Mestre pelo PPG em Geografia da Universidade Federal do Espírito Santo - josimar.histogeo@gmail.com.
\end{abstract}

Recebido em 30/06/2019. Aceito para publicação em 30/07/2019.

Versão online publicada em 10/09/2019 (http://seer.ufrgs.br/paraonde)

\begin{abstract}
Resumo:
O trabalho aborda a reflexão ontológica na Geografia a partir do pensamento de Heidegger. O objetivo é demonstrar que o modo com o qual se deu tanto a influência do pensamento de Heidegger no Geografia humanista; quanto, a reflexão sobre a ontologia na Geografia crítica-radical, obstruíram o alcance que o seu pensamento poderia assumir para tratar a fundamentação ontológica na disciplina.
\end{abstract}

Palavras-chave: Ontologia; Fenomenologia; Geografia.

\begin{abstract}
:
The paper approaches the ontological reflection in Geography from the thinking of Heidegger. The aim is to demonstrate that the way in wich Heidegger's thinking was influenced so much in Humanist Geography; as well as the reflection on ontology in Critical-radical Geography, obstructed the scope that his thought could take to deal with the ontological foundation in the discipline.
\end{abstract}

Key-words: Ontology; Phenomenology; Geography

\section{Introdução}

O trabalho propõe prestar uma contribuição à investigação sobre a fundamentação ontológica do espaço na Geografia, problematizando-o através do diálogo renovado com o pensamento de Martin Heidegger. Trata-se de um caminho de problematização que encontra subsídios em contribuições relativamente recentes dedicadas ao assunto (Elden, 2001, 2004, 2005, Joronen, 2010; Schatzki, 2007; Strohmayer, 1998).

A fundamentação ontológica da ciência geográfica, enquanto tema, e a fenomenologia-hermenêutica de Heidegger, enquanto método, exprimem os dois elementos centrais do trabalho. Esses elementos possuem um lastro tão inequívoco quanto complexo na ciência geográfica. É possível, entretanto, reconhecer que ambos assumem maior expressão no debate teórico da geografia a partir da década de 1970, no contexto do movimento de renovação, notadamente através dos horizontes "humanista" e da "crítica-radical" (Gomes, 1996).

É amplamente reconhecida a associação entre, por um lado, o "horizonte humanista" e a fenomenologia; e, por outro lado, a reflexão ontológica desenvolvida no "horizonte da crítica-radical" sob influência decisiva do pensamento marxista. A confluência subsequente desses horizontes e a convergência correlata de temáticas e matrizes 
filosóficas (Kobayashi; Mackenzie, 1989; Ley, 1989; Gomes, 1996), que lhe é constitutiva, foi conduzida, em grande medida, com base nos padrões de codificação dos temas (e interlocução com as matrizes filosóficas) estabelecidos previamente no interior de cada horizonte.

A reflexão que se pretende desenvolver tem por objetivo demonstrar que o modo com o qual se verificou, por um lado, tanto a proveniência da influência do pensamento de Heidegger através do horizonte humanista quanto, em igual medida, o estatuto de fundamentação ontológica instaurado no horizonte da crítica-radical, obstruíram - por razões distintas - o alcance e até mesmo a apreensão do significado que o pensamento de Heidegger poderia assumir para tratar a fundamentação ontológica na disciplina. Para tanto o presente trabalho visa demonstrar o modo como essa obstrução se manifesta, bem como apontar para uma posição que constituiria uma alternativa de liberação dessa obstrução.

\section{A obstrução dos horizontes da crítica-radical e humanista ao problema da fundamentação ontológica na geografia através de Heidegger}

O objetivo do texto reflete uma posição sobre o assunto, qual seja: a reabilitação do problema da fundamentação ontológica constitui o foco sobre o qual uma ciência específica - a geografia, por exemplo - deveria se restringir, a fim de permitir que o elemento propriamente fenomenológico do pensamento de Heidegger possa ser conquistado e aberto ao desenvolvimento em uma ciência. O primeiro passo, no sentido dessa reabilitação, consistiria em legitimar a imprescindibilidade do geógrafo assumir a analítica do ser-aí (procedimento que constitui a fonte da elaboração da questão acerca do sentido do ser na ontologia fundamental de Ser e Tempo) antes das requisições que Ihe são usualmente atribuídas, notadamente nas esferas da pesquisa aplicada ou epistemológica. Quando se considera o modo com se efetivou na ciência geográfica tanto a reflexão ontológica quanto, sobretudo, a assimilação do pensamento de Heidegger a posição acima esposada não é, de modo algum, evidente - a despeito de contribuições que apontam nesse mesmo sentido (Pickles,1985; Elden, 2001, 2004, 2005; Joronen, 2010; Strohmayer, 1998;).

Para amparar a posição assumida, destacam-se dois elementos irredutíveis à fenomenologia-hermenêutica de Heidegger (2006): (i) "A ontologia só é possível como fenomenologia" (Heidegger, 2006; p.75) na medida mesma em que a “fenomenologia é a ciência do ser dos entes - é ontologia" (Heidegger, 2006; p.77); (ii) A analítica do ser-aí constitui "o primeiro desafio à elaboração da questão do ser" (Heidegger, 2006; p.54) e, assim, “É por isso que se deve procurar, na analítica existencial do ser-aí, a ontologia fundamental de onde todas as demais podem originar-se" (HEIDEGGER, 2006, p.49), o que incluiria, sob essa orientação, a ontologia do espaço na ciência geográfica.

\subsection{A supressão da questão do ser na reflexão ontológica da geografia crítica- radical}

O perfil da reflexão ontológica desenvolvido no "horizonte da crítica-radical", suscitou um retraimento - ainda que de modo indireto e derivado - às possibilidades de se desenvolver uma via de investigação sobre a fundamentação ontológica do espaço na geografia através do pensamento de Heidegger, por uma razão muito evidente, a saber: ao estabelecer um estatuto de resolução ontológica segundo o qual o ser é a 
sociedade, foi tacitamente suprimida a necessidade de se levantar a questão acerca do sentido do ser.

Trata-se de uma posição sobre o tema da ontologia estabelecida sob influência decisiva do pensamento marxista e que possui amplo alcance na disciplina. Seu alcance pode ser entrevisto, por exemplo, quando se considera a centralidade que a proposição da produção social do espaço assumiu na Geografia, na medida em que esta proposição - divisada através da influência saliente, embora não exclusiva, com a obra de Henri Lefebvre - constitui uma expressão estrita da vigência do referido estatuto. Caberia destacar, também, o papel que a Ontologia do Ser Social assumiu para contribuições que se dedicaram à abordagem explícita da ontologia na geografia crítica-radical (Silva, 1982; Moraes, 1982; Moreira, 2012).

O referido estatuto, pode se manifestar de modo expresso ou mitigado. No primeiro caso através de assertivas tais como "O ser é a sociedade total, o tempo são os processos, e as funções, assim como as formas são a existência [...]" (Santos, 2008 p.218, grifo nosso). Sua vigência mitigada se manifestaria em toda pesquisa (teórica ou empírica) tributária da noção de produção social do espaço, mesmo no caso de publicações teóricas que, sob esse enquadramento, desconsiderem a legitimidade de se desenvolver uma ontologia do espaço em geografia através do marxismo, porquanto entendem a reflexão ontológica incompatível ao pensamento de Marx (Carlos, 2011, p. 146). De qualquer modo, vigorando de modo expresso ou inexpresso, a resolução ontológica debitária da determinação social do ser passa ao largo da questão considerada filosoficamente primordial por Heidegger, a saber, a questão da diferença ontológica entre ser e ente. ${ }^{1}$

Assim, na medida em que através da determinação social do ser se compreende previamente o ser enquanto ser social, a questão do ser não pode, enquanto questão, constituir um problema efetivo para o horizonte da crítica-radical. Por isso, tanto a questão do ser é preterida, quanto, igualmente é preterida a fenomenologia como a via de acesso que revelaria a necessidade e primado da questão do ser (Heidegger, 2013; p. 46-47; p. 75). É oportuno destacar aqui a crítica que Sartre faz à Lukács e aos marxistas em geral no que respeita à interlocução com Heidegger: "Sim, Lukács tem os instrumentos para compreender Heidegger, mas não há de compreendê-lo porque seria necessário lê-lo, apreender o sentido das frases, uma a uma. Pelo que conheço, não existe nem sequer um marxista que seja capaz de fazê-lo" (Sartre, 2002 p. 43). A crítica de Sartre se desdobra, de maneira ainda mais incisiva, na nota de rodapé que acompanha a passagem citada:

\begin{abstract}
"É porque eles não conseguem se despojar de si mesmos: recusam a frase inimiga (por medo, ódio, preguiça) no próprio momento em que desejam abrir-se para ela. Essa contradição bloqueia-os. Não compreendem, literalmente, uma palavra do que leem. Não repreendo essa incompreensão em nome de não sei qual objetivismo burguês, mas em nome do próprio marxismo: sua rejeição e condenação será tanto mais rigorosa, sua refutação será tanto mais bem-sucedida na medida em que, antes de tudo, conhecerem o que condenam e refutam (SARTRE, 2002, p.43; nota de rodapé).
\end{abstract}

Desta forma, é bastante plausível inferir que, em função da intensidade com a qual o

\footnotetext{
${ }^{1}$ A interpelação entre, por um lado, a posição estabelecida sobre a ontologia do espaço no horizonte da crítica-radical em geografia sob a influência dominante do marxismo e, por outro lado, a questão da diferença ontológica entre ser e ente estabelecida por Heidegger, foi considerada por Reis (2009).
} 
pensamento marxista afetou a própria constituição da geografia crítica-radical, os geógrafos que se dedicaram à reflexão ontológica nesse horizonte tenham reproduzido, voluntaria ou involuntariamente, o "gesto" de Lukács em relação a Heidegger. A renovação do diálogo com Heidegger que recentemente os geógrafos têm procurado desenvolver permite rever os termos da relação entre o pensamento deste filósofo com o marxismo, como atestam as contribuições de Stuart Elden (2004a; 2004b) que trazem à tona a influência insuspeita do filósofo alemão no projeto intelectual de Lefebvre referência canônica para a renovação crítica-radical em Geografia - como atesta a passagem abaixo:

\begin{abstract}
"O trabalho de Heidegger é extremamente importante para o entendimento do projeto intelectual de Lefebvre. Sugere-se que o trio de pensadores [Hegel, Marx e Nietzsche] que influenciaram Lefebvre é [o mesmo] partilhado por Heidegger. (...). Há diferenças - muitas - entre Marx e Heidegger, mas, para Lefebvre, os dois são essenciais. Como bem notaram Kofman e Lebas, Heidegger foi o filósofo do século $X X$ em quem Lefebvre mais se engajou. D. Harvey sugeriu que uma combinação entre Marx e Heidegger é uma área promissora para futuros trabalhos quando argumentou sobre a "possibilidade de alguma forma concatenar a concepção marxista e heideggeriana dentro de um novo tipo de política radical". Esses insights e possibilidades continuam pouco desenvolvidos na literatura. [...]. Assim, podemos sugerir que a obra de Lefebvre demonstra a possibilidade de um heideggerianismo de esquerda. [...]. Lefebvre pode, portanto, ser beneficamente lido no nível político e filosófico entre Marx e Heidegger (Elden, 2004a, p. 101).
\end{abstract}

Trata-se de uma perspectiva de interlocução com Heidegger sensivelmente distinta daquela que foi dispensada ao pensamento deste filósofo no bojo da Geografia humanista, que emergiu sobretuto no contexto de renovação a partir da década de 1970. Contudo, a despeito da maneira com a qual as contribuições recentes poderiam, eventualmente, afetar a pesquisa sobre ontologia do espaço na geografia, requalificando o diálogo com Heidegger, o modo prevalente com o qual a reflexão ontológica sobre o espaço se estabeleceu no horizonte da crítica radical passa ao largo da questão sobre o sentido do ser e, assim, é alheia ao problema da diferença ontológica entre ser e ente. Sob esse ângulo de consideração, alinhado à fenomenologia-hermenêutica de Heidegger, o perfil dominante com o qual a reflexão ontológica sobre o espaço se efetivou no horizonte da crítica-radical seria destituído de "evidência fenomenológica".

De modo algum é sugerido que a "falta de evidência fenomenológica" constitui uma deficiência ao modo com o qual a geografia crítica-radical problematiza a fundamentação ontológica na Geografia - na medida em que ela é desenvolvida em consonância com um parâmetro de filiação filosófica marxista para o qual a "evidência fenomenológica" não constitui falta alguma. Tratar-se-ia, antes, de uma lacuna que deveria ser investigada no modo com o qual a fenomenologia, ao menos sob cunhagem que Heidegger Ihe imprimiu, foi considerada na Geografia. Se a questão do ser ainda hoje pode ser considerada mais ou menos relevante entre os geógrafos, em função da filiação a diferentes matrizes filosóficas, isso é indicativo, antes de tudo, do caráter insuficiente do modo com o qual o significado da própria fenomenologia foi assimilado nesta ciência. Esse problema aponta para a relação que os geógrafos estabeleceram com o pensamento de Heidegger no contexto do horizonte humanista da geografia. 


\title{
2.2 A obstrução humanista à reabilitação do problema da fundamentação ontológica na geografia.
}

O caráter problemático da assimilação da fenomenologia na Geografia humanista é amplamente reconhecido, (Gomes, 1996, p. 122-123; p. 305; Pickles, 1985). A crítica da assimilação humanista do pensamento de Heidegger na Geografia constitui o cerne deste item. Nesse sentido é imprescindível demonstrar, preliminarmente, a incompatibilidade crassa entre o pensamento do filósofo e o humanismo.

Essa incompatibilidade é trazida à tona de maneira absolutamente inequívoca na Carta sobre o humanismo, publicada em 1947 com o propósito de remediar os equívocos que, então, acometiam a direção na qual o filósofo pensou o homem em sua principal obra, Ser e Tempo. Então, Heidegger, partindo do sentido profundamente crítico que imputa à "Metafísica" - enquanto correlato histórico-civilizatório ocidental que manifesta o esquecimento do ser - expõe sua posição sobre o humanismo nos seguintes termos:

\begin{abstract}
Todo humanismo ou se funda numa metafísica ou se converte a si mesmo em fundamento de uma metafísica. Toda determinação da Essência do homem, que já pressupõe, em si mesma, uma interpretação do ente sem investigar - quer o saiba ou não - a questão sobre a Verdade do Ser, é metafísica. (...). Em consequência, todo humanismo permanecerá sempre metafísico. Ao determinar a humanidade do homem, o humanismo não só não questiona a re-ferência do Ser à Essência do homem. Ele até impede tal questionamento uma vez que, devido à sua proveniência da metafísica, nem o conhece nem o entende. (Heidegger, 2009 [1947]pp. 37 grifo nosso)
\end{abstract}

Como será observado no desenvolvimento do texto, a objeção do filósofo em relação ao humanismo não constitui uma posição refratária ao humanismo per si, isto é, não se trata de uma postura de rejeição obtusa e generalista ao humanismo enquanto tal, que, assim, estaria incitando uma posição filosófica em favor do desumano ou do inumano. De modo algum. Trata-se, contudo, de uma adevertência - registrada pelo próprio filósofo - de que a experiência própria ao pensamento filosófico que ele procurou desenvolver (e para o qual a publicação de Ser e Tempo constituirá uma referência insígne para todo o curso de seu pensamento) não é compatível com o tipo de pensamento característico do humanismo. A propósito, esta incompatibilidade constitui um traço que atravessa, sustentando, praticamente a integralidade da Carta sobre $o$ Humanismo, de tal modo que ela é reiteradamente ratificada por Heidegger sob os mais diversos ângulos de consideração, como torna patente a citação abaixo:

[...] temos primeiro que esclarecer como o Ser atinge o homem e o requisita. Essa experiência Essencial, nós fazemos quando nos ocorre que o homem é, enquanto eciste. (...). Com essa determinação da Essência do homem não se declaram falsas nem se rejeitam as intepretações humanistas do homem, como animal rationale, como "pessoa", como ser dotado de alma, espírito e corpo. Ao contrário, o único pensamento a se exprimir é que as determinações humanistas da Essência do homem, ainda mesmo as mais elevadas, não chegam a fazer a experiência do que propriamente é a dignidade do homem. Nesse sentido o pensamento de Ser e Tempo é contra o humanismo. (Heidegger, 2009 [1947]pp. 49 - 50). "Suposto que um título ["humanismo"] tivesse alguma importância, será que esse pensamento [no elemento de Ser e Tempo], ainda poderia ser designado como humanismo? De certo que não, enquanto o humanismo pensa metafisicamente (id. Ibid. pp. $55-56$, grifo nosso). 
É patente que mesmo a mais elaborada engenharia retórica teria muita dificuldade para sustentar a pertinência da filiação ao pensamento do filósofo para amparar uma "corrente humanista" numa ciência. Não sendo, contudo, suficiente essa indicação, cabe destacar a reserva que o próprio Heidegger manifestou em relação ao sentido de se tentar conservar o uso da palavra "humanismo":

[...] 'De que maneira se pode restituir um sentido à palavra, 'humanismo'? Sua pergunta não pressupõe somente que 0 Senhor $^{2}$ pretende conservar a palavra 'humanismo'. Ela implica também o reconhecimento que essa palavra perdeu o seu sentido".

E o perdeu por se haver percebido que a Essência do humanismo é metafísica, e isso significa agora, por se haver percebido que a metafísica não só não coloca a questão sobre a Verdade do Ser, mas a obstrui, enquanto persiste no esquecimento do Ser. (id. Ibid, pp $71-72$ ). (...).

Será que ainda se pode chamar de "humanismo" esse "humanismo", que se pronuncia contra todo humanismo vigente, mas sem advogar, de maneira alguma, o inumano? E somente para, talvez participando no uso do título, nadar nas correntes [humanistas] em voga, que se afogam no subjetivismo metafísico e submergem no esquecimento do Ser? Ou não será que o pensamento, por meio de uma oposição aberta ao humanismo, não deve antes suscitar um escândalo, capaz de despertar, primeiro, a atenção sôbre a humanitas do homo humanus e sua fundamentação? (...) Será que não deveríamos suportar, ainda por algum tempo, os mal-entendidos, a que vem sendo exposto o pensamento no elemento de Ser e Tempo, e deixar que se gastem lentamente? Esses mal-entendidos são, naturalmente, interpretações do que se lê ou mesmo do que se pretende ter lido, segundo o que se crê já saber antes da leitura (id. Ibid. pp. $73-74$, grifo nosso).

O humanismo é, assim, exposto como tributário de um modo de pensar o homem que não somente passa ao largo da questão acerca do Ser, como impedira a apreensão do sentido da elaboração da questão ${ }^{3}$. Cabe notar que não se trata de uma posição circunstancial do filósofo: na medida em que a elaboração da questão do ser constitui a diretriz de toda a sua obra (Borheim, 1970), a crítica por ele dispensada ao humanismo é intrínseca à integralidade de sua obra. O recurso mesmo ao título "humanismo" é entrevisto por Heidegger como um indício da vigência do pensamento caracteristicamente metafísico que, para ele, é correlato do subjetivismo metafísico que obstrui o acesso à questão do ser e, por extensão, ao elemento mais próprio de seu pensamento. Nestes termos, somente através de uma profunda deturpação da posição do filósofo acerca do humanismo seria possível permanecer recorrendo ao seu pensamento como uma "matriz fenomenológica" para fundamentar uma "concepção humanista" da ciência. Deturpação esta que, entretanto - como será demonstrado no que segue - ainda grassa de modo insidioso na disciplina, particularmente em contribuições de geógrafos que têm aspirado à filiação da Geografia humanista, como atesta a citação abaixo:

\footnotetext{
${ }^{2}$ Trata-se de Jean Beaufret, para quem Heidegger endereçou a carta escrita em 1946 que foi publicada no ano seguinte.

${ }^{3}$ Embora o presente texto se limite em considerar a fenomenologia de Heidegger, a despeito das diferenças fundamentais que existem em relação à fenomenologia de Husserl, no que concerne ao problema particular do humanismo, o conteúdo mesmo da fenomenologia husserliana é convergente à posição de Heidegger. Como observou Casanova: "Já em Husserl, portanto, não há mais como falar de uma substancialidade humana e, por conseguinte, de um humanismo metafísico com bases fenomenológicas" (Casanova, 2017; p. $30-31$ )
} 


\begin{abstract}
"Os geógrafos têm buscado a experiência humana sobre a Terra e este objetivo coaduna com o esforço dos fenomenologistas. Por isso, entendemos que as concordâncias entre ambos revelam um sentimento humanista maior de desejo de colocar o homem como medida e valor para um humanismo autêntico, primando pela humanidade do homem humano, como o quis Heidegger (1991 [1947]) e como o queremos hoje" [...]"Eis o desafio que vemos à frente para a ciência e para a Geografia: [...]. Conseguir ter uma ciência permeada pelo Humanismo e pela Abordagem Cultural, sem perder nossas raízes e tradições. É a proposta de uma ciência humanista e orgânica, consubstanciada entre o material e o imaterial, mas com um valor de medida: o homem". (Marandola Jr, 2005, pp.77 78 , grifo nosso).
\end{abstract}

A discrepância entre a posição do filósofo e a interpretação que lhe é imputada não poderia ser maior. Não se trata, contudo, de um deslize de interpretação fortuíto, mas a evidência de uma radical incompreensão em relação ao que está questão no âmbito do pensamento de Heidegger $e$, por isso, encerra um traço tão constitutivo quanto problemático de interpretação conduzida sob os auspícios do horizonte humanista na Geografia. Essa interpretação, terá, por sua vez, consequências restritivas que iráo afetar até a assimilação de elementos que, de outra forma, poderiam ser considerados básicos para a recepção do pensamento deste filósofo nesta ciência. Contraste-se, por exemplo, a discordância da citação acima com a posição do filósofo acerca da vinculação entre "humanismo" e "valor" extraída de passagens do opúsculo Carta sobre o humanismo, quando, em meados da década de 1940, Heidegger procurou expor os mal entendidos que, desde então, observava como recorrentes à interpretação do pensamento contido em Ser e Tempo:

\begin{abstract}
(...)."Porque se fala contra o 'humanismo', teme-se que se defenda o inumano e se glorifique a brutalidade e barbaridade. Pois, o que é 'mais lógico' do que isto: quem nega o humanismo, não lhe resta senão afirmar a desumanidade? [...] Porque se fala contra os 'valores' surge uma indignação em face de uma filosofia que [...] se atreveria a desprezar os bens mais elevados da humanidade. Pois, o que é 'mais lógico' do que isto: um pensamento que nega os valores, terá necessariamente que declarar tudo sem valor? (Heidegger, 2009, p.74). [...]. O pensamento contra 'os valores' não afirma ser sem valor tudo que se considera como 'valores' [...]. Trata-se de se compreender de uma vez por todas, que ao caracterizar algo como um 'valor', se lhe rouba a dignidade. $O$ que quer dizer: ao se avaliar uma coisa como valor, só se admite o que assim se valoriza, como objeto de avaliação do homem. [...].Pensar em termos de valor é aqui, como alhures - a maior blasfêmia que jamais se possa pensar com relação ao Ser. (Heidegger, 2009, p.78; grifo nosso).
\end{abstract}

Ora, em consonância com o exposto acima, seria necessário reconhecer que a citação do geógrafo destacada anteriormente (Marandola, 2005) constituiria um exemplo patente do que o filósofo considera a "maior blasfêmia que jamais se possa pensar em relação ao Ser", na medida em que requisita o homem "como valor de medida" para uma ciência humanista - exatamente o que é destacado pelo filósofo como um gesto de destituição da dignidade do homem, característico da Metafísica. Na medida em que o ser constitui o assunto primordial da ontologia - e, também, a questão cardeal de Heidegger - deve estar também claro em que sentido o presente texto faz alusão à "obstrução" que o horizonte humanista pode exercer em relação à possibilidade de reabilitação do problema da fundamentação ontológica na geografia através de Heidegger. 
É importante reiterar que a divergência observada acima não constitui um equívoco episódico de interpretação que se restringiria ao trabalho do geógrafo humanista publicado em 2005. A vigência recorrente dessa divergência é flagrante em um número significativo de publicações - mesmo recentes - filiadas ao "coletivo humanista" (Marandola Jr. 2012; 2013; 2014b; 2016; Gallo; Marandola Jr.,2016 - dentre muitos outros, que assumem essa orientação interpretativa sobre a fenomenologia na geografia). Dentre estas, considera-se importante destacar o caráter contumaz com o qual essa leitura se efetiva, por exemplo, na seguinte passagem extraída da apresentação do livro "O espaço fora do lugar":

\begin{abstract}
O cenário teórico é de maior pluralidade em direção à superação da excessiva fragmentação. E como atestam as contribuições aqui reunidas, não vivemos uma era de ecletismo irresponsável, mas de potencialidades analíticas instigantes para se pensar o ser e,..., talvez até pensar a ontologia do espaço. [...] O pensar ontológico nunca foi mais necessário, por isso tantos recorrem atualmente a Heidegger para buscar respostas aos problemas da sociedade contemporânea. Os valores humanistas também nunca foram tão necessários frente a um mundo desumano e pernicioso. (Marandola Jr. 2014a. p. Xvii, grifo nosso).
\end{abstract}

Como é possível compreender uma divergência tão contundente da assimilação de Heidegger entre os geógrafos? Trata-se, como será evidenciado no que segue, da expressão de um anacronismo injustificado que acomete publicações que reincidem num problema já superado há décadas na disciplina. Para qualificar a natureza desse anacronismo no âmbito interno da Geografia recorre-se à contribuição do geógrafo John Pickles Phenomenology, Science and Geography. Spatiality and the human sciences publicado em 1985, cujo elemento mais importante para a presente reflexão incide na distinção entre a "Geografia fenomenológica" e "Fenomenologia geográfica". Esta última corresponderia à adaptação da filosofia fenomenológica fundada por Husserl às estruturas de significação dos conceitos geográficos tradicionais, levada a termo nas contribuições pioneiras do horizonte humanista na década de 1970 (Yi-Fu Tuan, Edward Relph, Anne Buttimer, etc...). Esta adaptação teria se convertido na única referência para os pesquisadores subsequentes dispunham sobre fenomenologia na disciplina (Pickels, 1985; pp. 5). O autor constatou, então, a necessidade de questionar a "Fenomenologia geográfica" dos pioneiros contrastando-a com 0 significado original da Fenomenologia fundada por Husserl e dos principais filósofos que a ela se filiaram e desenvolveran-na, dentre outros destacando-se, de maneira saliente no livro de John Pickles, a referência insínge de Heidegger. O "saldo" dessa contraposição aponta para a "Geografia fenomenológica". Esta corresponderia ao esforço de uma retomada da interlocução com os expoentes da filosofia fenomenológica (Husserl, Heidegger, etc), visando a depuração de uma base fenomenológica sólida para a ciência geográfica. O humanismo é "expelido" desse projeto na medida mesma em que o autor, com base em Heidegger, compreende que "a fenomenologia não pode ser nunca um "humanismo" (Pickles, 1985;p.48).

A crítica de Pickles à fenomenologia dos pioneiros da geografia humanista se impôs de modo incontornável para ele, de tal modo que é através desta crítica que, em última instância, o autor pôde fazer avançar as conquistas dos pioneiros, ou seja, não degradando o esforço científico (e, por extensão, também institucionalmente consistente) que eles efetivamente desemepenharam para que a assimilação da fenomenologia na Geografia ganhasse vulto. O projeto de uma "Geografia fenomenológica" permitira suplantar o padrão de codificação da "fenomenologia geográfica" dos pioneiros do 
horizonte humanista e, apontaria, outrossim, em direção à investigação da ontologia da espacialidade humana, que, para Pickles (1985, p.170) encerra um programa de pesquisa amplo. O trabalho deste geógrafo atesta que o aprofundamento da base fenomenológica na geografia não é compatível com o humanismo - coadunando com a posição estrita de Heidegger, exposta no início do presente item do artigo. Nesse sentido, uma Geografia fenomenológica não poderia ser concebida enquanto Geografia humanista em função da incompatibilidade intrínseca que o conteúdo significativo estrito dos termos "fenomenológico" e "humanista" exprimiriam.

Com base no exposto acima, cabe destacar que as publicações recentes filiadas ao horizonte humanista que permanecem imputando uma leitura humanista ao pensamento de Heidegger (Marandola Jr., 2014a, p. xiv; 2012; 2013; 2016; Marandola Jr. e Gallo, 2015b) apontam para uma perspectiva de tratar o assunto francamente divergente daquela divisada por Pickles (1985), em consonância estrita com a posição do referido filósofo. É indispensável, assim, interpelar mais detidamente o perfil destas publicações nas quais, a propósito, à leitura humanista do filósofo regularmente se faz acompanhar de indicações que visam, reiteradamente, exaltar a importância institucional da geografia humanista no panorama atual da pesquisa geográfica. Essa interpelação é de fundamental importância, na medida em que, o anacronismo da leitura humanista do filósofo pode consistir numa distorção e submissão de um problema científico legítimo (a relação entre a fenomenologia e o humanismo) em um pseudoproblema institucional, que se torna função da necessidade de legitimação institucional de um "horizonte" epistemológico de uma ciência. Nada mais distante, portanto, das diretrizes da fenomenologia-hermenêutica, por exemplo, de Heidegger. Além disso, seria propriamente nesse âmbito, qual seja, referente à dimensão institucional da geografia humanista que residiria, de fato, a raiz principial da obstrução que o horizonte humanista exerceria à possibilidade de se resgatar a investigação acerca da fundamentação ontológica do espaço na geografia através das coordenadas estritas do pensamento de Heidegger.

Destaque-se, no sentido viabilizar o encaminhamento proposto no parágrafo precedente, a sequência de citações que serão objeto de análise no que segue, especialmente instigantes por terem sido extraídas de uma publicação que, além de evocar expressamente a filiação à Geografia humanista tem o objetivo de realizar um balanço panorâmico, no início da presente década de 2010, sobre a relação entre a Geografia humanista e a fenomenologia. Trata-se do artigo intitulado "Fenomenologia e Pós-fenomenologia: alternâncias e projeções do fazer geográfico humanista na geografia contemporânea" (Marandola Jr., 2013). Nesta publicação, após passar em revista o papel da fenomenologia na constituição da geografia humanista "estadunisense" na década de 1970, e seus desdobramentos nas décadas subsequentes, é oferecida a seguinte apreciação:

\footnotetext{
"Por conta desse processo, a geografia humanista, como um todo, não se aprofundou na fenomenologia ao ponto de constituir ou propor uma geografia fenomenológica. Os geógrafos deste movimento [de renovação humanista na geografia] escavaram até certo ponto (com exceção de Relph), e diante das dificuldades inerentes de se incorporar um sistema filosófico heterodoxo como a fenomenologia ao fazer científico, satisfizeram-se com a renovação conceitual que haviam conseguido e com as aberturas que se constituíram. Uma conclusão comum a autores como Entrikin (1976), Buttimer (1976) e Tuan (1976) era que a fenomenologia era mais útil como uma orientação, como uma postura, e que ela teria limites muito claros, especialmente para a operacionalização de pesquisas empíricas" (...). Considero esta perspectiva completamente superada
} 
atualmente, com avanços e pesquisas suficientemente consistentes que mostram que a hesitação na época era circunstancial, talvez fruto do próprio estado da pesquisa fenomenológica, que ainda carecia de muitas traduções e conhecimento de textos-chave de Husserl e Heidegger, por exemplo, cuja possibilidade de pensamento espacial em ambos ainda era embrionária ou simplesmente inexistente" (Marandola Jr.; 2013: 53).

A citação acima é iniciada com um argumento que, a princípio, poderia ser considerada estritamente convergente àquele proposto por Pickles (1985), porquanto sinaliza que a geografia humanista não teria se aprofundado na fenomenologia, limitando, assim, a possibilidade de constituir uma geografia fenomenológica. Uma análise mais detida da passagem revela, contudo, que não é esse - absolutamente - 0 caso. Isso pode ser aferido, de modo irreprochável, quando se constata que o autor assevera que os limites que teriam restringido 0 aprofundamento da filiação fenomenológica na Geografia humanista configuraria uma situação "completamente superada atualmente", com o claro propósito de reafirmar, no contexto atual da pesquisa em geografia, a pertinência de se requisitar uma filiação à fenomenologia para fundamentar uma perspectiva humanista na Geografia. Trata-se, portanto, de um encaminhamento fundamentalmente divergente da posição de Pickles (1985), mas, além disso, como vimos anteriormente, é antes de tudo incompatível com a posição sobre o humanismo expressa pelo próprio Heidegger - filósofo que, é importante ressaltar, foi nomeadamente referido na citação. A mesma citação traz à tona, ainda, inferências que não podem passar incólumes, porquanto afetam direta e negativamente a própria inteligibilidade do assunto em nossa disciplina.

Em primeiro lugar, indicar, a "carência de traduções e conhecimento de textos-chave de Husserl e Heidegger" (Marandola Jr., 2013) como possíveis causas que teriam limitado a assimilação consistente da fenomenologia no contexto da constituição da geografia humanista constitui um argumento que, ao menos no que diz respeito à difusão editorial da obra de Heidegger, não encontra amparo algum. As traduções para a lingua inglesa de Ser e Tempo e Carta sobre o humanismo foram publicadas em 1962 (Hemming, 2013;jp. 281; p. 284), disponibilizadas, portanto, praticamente com uma década de antencedência da constituição da geografia humanista "estadunisense" ganhar vulto. A primeira tradução brasileira de Carta sobre o humanismo foi publicada em 1967, como o título abreviado Sobre o humanismo. ${ }^{4}$ Por conseguinte, não faz sentido, ao menos em relação ao caso da obra de Heidegger, sugerir que a pesquisa fenomenológica, então - à época de constituição da geografia humanista "estadunisense" - não dispunha de acesso a textos-chave, mas apenas de textos em que "o pensamento espacial" era "embrionario ou inexistente". Esse argumento não faz sentido pois isso implicaria, por um lado, minimizar o significado de "texto-chave" de Ser e Tempo no conjunto da obra do filósofo, como, por outro lado, significaria subestimar o papel absolutamente central que o problema do espaço assume para viabilizar formulações fundamentais em Ser e Tempo. Pelo quanto afetam o que está em jogo na recepção do pensamento de Heidegger na ciência geográfica, é preciso chamar à atenção e aprofundar, ainda que de modo condensado, uma contraposição interpelativa às sugestões contidas no texto acima citado do geógrafo humanista. A rigor, os argumentos que encerram a citação acima induzem uma leitura sobre a pesquisa fenomenológica que, no caso estrito da obra de Heidegger, promove em última instância uma trivialização do significado histórico que Ser e Tempo representou no que concerne

\footnotetext{
${ }^{4}$ A primeira tradução brasileira de Ser e Tempo foi editada entre os anos de 1985 - 1986 (Kahlmeyer-Mertens, 2013, p. 169) com a publicação segmentada em duas partes, respectivamente, em 1988 e 1989.
} 
à filosofia fenomenológica do século $X X$, isto pois, não haveria publicação que exerce de modo mais emblemático o papel de "texto-chave" no conjunto da obra do filósofo do que Ser e Tempo, que é, por sua vez, sobejamente considerado como representativo da fase de seu pensamento em que o caráter metodológico da fenomenologia teria sido formulado de forma mais "paradigmática" em sua extensa obra, como é possível entrever, ainda que de modo discreto, destacando-se o título do sétimo parágrafo da Introdução de Ser e Tempo, a saber: "§. O método fenomenológico da investigação" que se tornou uma referência canônica - para dizer o mínimo - na literatura especializada na pesquisa fenomenológica. Por sua vez, no mesmo sentido, a discussão sobre o problema do espaço é absolutamente central, também, desde a Introdução de Ser e Tempo, quando são feitas as indicações preliminares acerca do vínculo intextrincável entre o ser-aí (Da-sein) e o mundo, que confluem para a descrição do fenômeno "ser-nomundo" no $\S 12$, quando o espaço é expressamente problematizado como fenômeno originário através da exposição do existencial "ser-em", antecipando as análises contidas na sequência de parágrafos $(\S 22, \S 23$ e $\S 24)$ que são integralmente reservados à descrição fenomenológica da espacialidade do ser-ai ${ }^{5}$.

As ressalvas feitas acima são relevantes, na medida em que permitem - antes de retomar a análise interpelativa com as publicações filiadas à Geografia humanista redimensionar o cerne da crítica levada a termo neste momento do texto, através de um argumento mais incisivo, qual seja: se os geógrafos ainda não tiveram condições de apreender a incompatibilidade entre o pensamento de Heideggeer e qualquer laivo de humanismo a partir da estudo de Ser e Tempo (ponderando a envergadura da obra e a inflexão que provocou no pensamento filosófico do século XX) - é de causar espanto que a clareza solar com a qual o próprio filósofo se posiciona na Carta sobre o humanismo não tenha sido o suficiente para conter qualquer impulso no sentido de fomentar uma confluência entre uma ciência humanista e o pensamento do filósofo. Essa advertência não diz respeito, por sua vez, somente a um problema de interpretação generalista sobre o pensamento do filósofo, mas se articula, diretamente, no que concerne especificamente ao modo com o qual os geógrafos encetam uma interlocução com sua obra em relação ao problema do espaço. E isto, por uma razão bastante simples: uma concepção humanista da ciência geográfica e do espaço é necessariamente não-fenomenológica, tanto quanto uma ciência geográfica em bases fenomenológicas implica uma problematização do espaço que náo é acessível ao pensamento humanista. Dito de modo conciso: em consonância com Heidegger, onde vigora o humanismo não pode haver fenomenologia e onde vigora a fenomenologia não pode haver humanismo, senão através de uma deturpação do significado estrito que o filósofo imputa à fenomenologia e ao humanismo.

Considerando as ressalvas acima, é bastante razoável depreender que a análise que o geógrafo humanista (Marandoja Jr., 2013), irá desenvolver ao focalizar a relação entre

\footnotetext{
${ }^{5}$ Acolher tese, bastante difundida entre os comentadores e especialistas de Heidegger, segundo a qual no período posterior à fase de Ser e Tempo o "problema" do espaço é redimensionado, assumindo uma centralidade que, à época de Ser e Tempo teria sido minimizada pela ênfase dispensada ao tempo, embora possa corresponder a uma inferência correta do ponto de vista da interpretação da obra do filósofo, não constitui per si um avanço no que respeita à sua assimilação na ciência geográfica. Mesmo a ampliação significativa do número de publicações especificamente dedicadas à "dimensão espacial" em Heidegger, levada a termo no âmbito do debate filosófico contemporâneo por pesquisadores como Jeff Malpas, Edward Casey, Ligia Saramago; Schatzki dentre outros - não significa, necessariamente, uma garantia de que a assimilação da problemática sobre o espaço contida na obra de Heidegger será efetivada de modo mais consistente numa ciência particular, como no caso da Geografia. Ao contrário, essa literatura especializada sobre a "filosofia do espaço" em Heidegger pode representar um extravio à assimilação consistente de seu pensamento acerca do espaço, sendo o suficiente, para tanto, que induza a impressão de que é possível apreender o sentido que o problema do espaço assume na fase da obra de Heidegger posterior a Ser e Tempo - preterindo, assim, as conquistas da descrição fenomenológica do espaço nesta obra.
} 
a fenomenologia e a geografia humanista no contexto da pesquisa brasileira em geografia será debitária dos problemas e limitações de sua interpretação ao tratar o assunto sob um enquadramento mais amplo, referente à constituição e desenvolvimento do horizonte humanista em geral. Importa, entretando - a despeito da miríade de elementos que poderiam ser profícuamente problematizados sob uma perspectiva crítica - concentrar a análise sobre um elemento que até o momento permaneceu apenas insinuado, qual seja: a ênfase dispensada, nestas publicações, à auto-afirmação institucional da geografia humanista, em detrimento de uma problematização consequente em relação à fenomenologia. Esse elemento vem à tona de modo pregnante na passagem abaixo, na qual o autor oferece a seguinte síntese sobre a relação entre a relação entre a fenomenologia e o horizonte humanista na pesquisa brasileira em geografia:

\footnotetext{
"O resultado é muito interessante para pensar. Se até os anos 1990, o máximo que esse horizonte de pensamento recebia nos manuais ou avaliações de história do pensamento geográfico era uma menção aos estudos sobre percepção do meio ambiente oriundas da UNESP de Rio Claro, no últimos anos cresce 0 reconhecimento da abordagem fenomenológica da geografia como um campo consolidado e ativo da geografia feita no Brasil. Mais do que isso, ela aparece nominalmente como o eixo principal, ou seja, como a imagem que esse horizonte está recebendo (....).

"Isso acontece, de um lado, por essa renovação e retomada da discussão da fenomenologia, a qual radicaliza e dá continuidade ao esforço humanista dos anos 1970, e de outro, pela postura de pensar a fenomenologia na contemporaneidade, não hesitando em aplicá-la em estudos empíricos. Há o desenvolvimento de metodologias de trabalho de campo e o esforço de pensar os vários ramos da fenomenologia e suas consequências para a experiência no mundo atual (GRATÃO, 2002; MARANDOLA JR, 2005; 2008; CHIAPETTI, 2009; DE PAULA, 2010; HOLZER, 2010b; REIS, 2013) [...].

"Em outras palavras, ao invés de uma subcorrente do pensamento geográfico, apresenta-se como esteio metodológico e epistemológico (as vezes até ontológico), para o enfrentamento de temáticas variadas, a partir de uma perspectiva de ciência humanista contemporânea (Holzer, 2010c; Marandola Jr.,2012 (Marandola Jr. 2013, p. 55 - 56, grifo nosso).
}

O que chama à atenção de modo peculiar na citação acima é que ela revela, de modo patente, que o problema da incompatibilidade entre a fenomenologia e o humanismo é solenemente ignorado, ao mesmo tempo em que é reiteradamente pontuado uma série de inferêcias dedicadas à reafirmação da relevância institucional da Geografia humanista. Não seria exagerado, nesse sentido, propor que o problema substantivo da relação entre a fenomenologia e o humanismo submerge diante do afã de reiterar a pretensa relevância institucional da geografia humanista. Não é, absolutamente, excessivo sublinhar o caráter pretenso da necessidade de auto-afirmação institucional do horizonte humanista nos termos referidos na citação acima, na medida em que a relevância que o autor imputa à geografia humanista seria debitária de uma suposta base fenomenológica que a pesquisa em geografia humanista recente teria divisado à geografia. Na medida em que a fenomenologia é incompatível com o humanismo, toda assertiva dedicada à apologia da geografia humanista que se efetiva sublinhando sua filiação à fenomenologia, resta, necessariamente inócua e, somente por isso, tornam pretensiosos os argumentos dedicados à apologia da geografia humanista. Dessa maneira a filiação à fenomenologia é transfigurada à condição de um meio cuja finalidade precípua é, antes de tudo, exaltar a importância da geografia humanista essa atitude é, ela própria, uma pretensão destituída de fundamento, pois ela se faz não 
somente trivializando a fenomenologia, mas em detrimento da fenomenologia. Esse quadro coloca, por sua vez, em suspeição a consistência do desenvolvimento de metodologias de campo e dos estudos empíricos derivados da retomada da fenomenologia em curso nos estudos recentes da Geografia humanista que, supostamente, radicalizam e dão continuidade ao esforço humanista dos anos 1970, por uma razão muito simples, a saber: os referidos "avanços" implicam, necessariamente, desconsiderar a incompatibilidade entre a fenomenologia e o humanismo. Na medida em que a leitura humanista da fenomenologia constituiria uma transfiguração de base desta última, derivar desta leitura a elaboração de metodologias de campo e estudos empíricos depõe contra a própria consistência destes trabalhos, na medida em que seriam tributários de uma amparo filosófico corrompido.

Não deve surpreender, portanto, que o enlace argumentativo do autor, à guisa de síntese sobre os rumos da geografia humanista brasileira, reitere a perspectiva de convergência entre a geografia humanista e a fenomenologia, através de uma exortação institucional deste horizonte na geografia brasileira, que se revela, ao fim e ao cabo, como a razão fundamental deste tipo de publicação:

\footnotetext{
"Por que essa mudança de ênfase na fenomenologia é importante? Primeiramente, porque podemos identificar uma mudança na institucionalização desse horizonte na geografia brasileira: o que somos acostumados a chamar de geografia humanista, especialmente pela continuidade que identificamos com esses movimentos dos anos 1970, e que por muitos anos teve uma conotação muito negativa nas demais áreas da geografia, ora vista como não-científica, ora como nãopolítica, hoje parece ter conseguido seu espaço. Isso tem acontecido especialmente pelo esforço epistemológico de continuar o trabalho iniciado, e não acabado, pelos geógrafos humanistas de constituir uma geografia eminentemente fenomenológica, razão pela qual o termo fenomenologia, anteriormente não representativo deste coletivo no Brasil, hoje o é (Marandola Jr., 2013; 56, grifo nosso).
}

É com base no exposto acima que entende-se como pertinente considerar, como foi sugerido anteriormente, que a reincidência da interpretação humanista da fenomenologia-hermenêutica de Heidegger pode ser considerado como expressão de uma deturpação institucional de uma problemática científica legítima, referente à relação entre a fenomenologia e o humanismo. Chega-se, forçosamente a esta conclusão, pois somente ponderando uma motivação externa à esfera mais estritamente científica é possível compreender a realização de leituras que promovam uma desarticulação tão profusamente desagregadora em relação aos elementos da proboemática em questão.

Esse quadro terá, evidentemente, consequências severas sobre as publicações que, a partir da orientação qualificada acima, foram estritamente dedicadas à análise da influência do pensamento de Heidegger na ciência geográfica (Marandola Jr., 2012), ou, mais especificamente, sobre na obra de Eric Dardel (Marandola Jr., 2011; Marandola Jr.; Gallo, 2015) e no livro de Edward Relph Place and Placelessness (Marandola Jr., 2016). O problema inerente dessas publicações diz respeito ao fato de que elas são dedicadas ao contrassenso de inferir a influência do sreferido filósofo nesta ciência a partir de uma orientação não apenas diversa, mas frontalmente contrária a resoluções irredutíveis ao seu pensamento. De modo sintético, essas publicações acabam gerando o resultado contrário aquele que poderia representar uma contribuição efetiva à inteligibilidade do pensamento de Heidegger na Geografia, pois, ao invés de fomentarem um esclarecimento sobre o seu pensamento a partir da explicitação dos limites com os quais ele foi assimilado no horizonte humanista, o compromisso sub-reptício, previamente 
estabelecido, de valoração do referido horizonte, faz com que se obscureça o entendimento do próprio pensamento do filósofo - porquanto, invariavelmente, as referidas publicações ratificam a pertinência da leitura humanista de Heidegger, vigente nas obras dos expoentes do horizonte humanista. Não é exequível, na presente análise, trazer detalhadamente à tona as contradições agudas que estas publicações incorrem, pois o problema de base da leitura humanista possui um efeito multiplicador sobre vários elementos concernentes à interseção entre a ciência geográfica e o pensamento de Heidegger. À guisa de ilustração, contudo, destaque-se na citação abaixo o argumento com o qual é concluída a análise da influência do filósofo sobre a obra de Edward Relph:

\begin{abstract}
"Se abrimos mão da autenticidade enquanto valor da identidade e da construção dos lugares, abriremos mão da possibilidade de outras formas de existência. E é por isso que manter-se alerta à posição de pastor do ser, assumindo a função do cuidado, continua sendo um dos legados mais fortes e perenes que Heidegger deixou para nossa era da técnica" (Marandola Jr., 2016, p. 14).
\end{abstract}

De imediato salta aos olhos, na citação acima, que o geógrafo humanista reincide no recurso a uma conotação subjetivista da noção de valor, o quê - como foi possível observar no início do presente item - é contrário à posição que o filósofo externou, de forma cabal, na Carta sobre o humanismo. Junto a isso, é patente que a acepção que é sugerida às formulações de "autenticidade" e "cuidado" estão em franco desacordo com o significado que elas possuem na obra de Heidegger: referir-se, por exemplo, ao "cuidado" (Sorge) como um atributo "moralmente" prescritivo e facultativo, que, portanto, poderia ser ou não assumido - enquanto uma função - é incorrer numa transgressão do significado que o próprio Heidegger imediatamente sublinha quando expõe o significado que a noção de "cuidado" possui em Ser e Tempo, a saber, não se trata de uma acepção ôntica do cuidado, isto é, não se trata de um traço fortuíto à existência humana, mas uma formulação que aponta para um traço ontológicamente constitutivo do existente (ser-aî). Dito de outro modo: a partir do pensamento de Heidegger não faz sentido prescrever a necessidade de se assumir a "função do cuidado" e, tampouco, através disso, alardear uma atitude voluntarista para a retificação da "construção dos lugares".

Nestes termos, ao que é dado depreender através da análise desenvolvida no presente item, o sentido com o qual a geografia humanista promove uma obstrução à assimilação consistente do pensamento de Heidegger e, por extensão, à possibilidade de encetar com base neste filósofo um programa de pesquisa dedicado ao resgate da investigação sobre a fundamentação ontológica do espaço na Geografia, deriva, em grande medida, da deturpação da leitura humanista de seu pensamento que, por sua vez, assenta na necessidade de auto-afirmação meramente institucional desse horizonte na disciplina. Essa necessidade preemente obseda, compromentendo, a intepretação do pensamento do filósofo nas publicações deste tipo, que foram aqui sumariamente analisadas. Em última instância, nestas publicações, não importa o sentido próprio do pensamento do filósofo, nem, tampouco o rigor (ou mesmo o respeito) para com a leitura de seus textos, mas, antes de tudo, importa muitíssimo requisitá-lo como signo de uma "suposta autoridade filosófica", que, ao ser assim associada à Geografia humanista, Ihe conferiria uma "aura" de consistência filosófica.

Por fim, a leitura humanista de Heidegger não é apenas inconsequente em relação à exegese filologicamente rigorosa da leitura das próprias obras do filósofo; não é, também, apenas destituída de acurácia para apreender as conquistas que publicações especialmente dedicadas ao assunto divisaram na disciplina - como no caso da obra de 
Pickles (1985). Tendo em vista, por exemplo, o tratamento rigoroso e consistente que o assunto conheceu no bojo do debate da teoria geral da geografia - como, por exemplo, contido na contribuição de Gomes (1996; p. 116 - 124) - a leitura humanista de Heidegger exprime, necessariamente, uma falta de preparo básico para lançar mão dos registros estabelecidos no seio do próprio debate teórico-metodológico sobre o assunto na disciplina - o que não se confunde, por sua vez, com um programa de investigação fenomenológica sobre as bases ontológicas da disciplina. Assim, o problema da leitura humanista do filósofo constitui não mais do uma - ainda que seja a mais saliente - de toda uma série de evidências das profundas contradições e fragilidades que acometem essa "chave-intepretativa" da fenomenologia na Geografia.

\section{Considerações Finais}

O presente texto propôs demonstrar que o modo com o qual se verificou, por um lado, tanto a proveniência da influência do pensamento de Heidegger através do horizonte humanista quanto, em igual medida, o estatuto de fundamentação ontológica instaurado no horizonte da crítica-radical, obstruíram - por razões distintas - o pensamento de Heidegger poderia assumir para tratar a fundamentação ontológica na disciplina.

Porquanto é na geografia humanista que a interlocução com o filósofo se estabeleceu, de modo peculiar, nesta ciência, a ênfase da análise incidiu sobre o referido horizonte. A crítica não se dirigiu ao horizonte humanista, enquanto tal, que é reconhecidamente uma vertente caracterizada pelo caráter eclético de filiações filosóficas. A análise se restringiu à crítica de trabalhos da geografia humanista que tornam problemática a assimilação de Heidegger na disciplina.

Em Ser e Tempo, a "analítica do ser-aí constitui o primeiro desafio à elaboração" concreta da questão do ser e, assim, constitui a fonte da ontologia de base "de onde todas as demais ontologias - inclusive à ontologia em geografia - pode originar-se "(Heidegger, 2013, p.49). Nesse sentido, as contribuições que não promovem um esclarecimento suficiente acerca do sentido da referida analítica não podem também esclarecer o sentido do pensamento do filósofo para uma ciência - ou o fazem de maneira insuficiente (Reis, 2009; 2012). O esclarecimento da referida analítica não pode se limitar, por sua vez, à exposição teórica dos seus elementos e, assim, é preciso que o significado da analítica do ser-aí para a elaboração concreta da questão do ser seja, efetivamente, disponibilizada entre os geógrafos - o que deslocaria a reabilitação do problema da fundamentação ontológica do plano estritamente teórico-metodológico para o plano existencial da produção da ciência. Isso, contudo, não tem nada a ver com a operacionalização do pensamento do filósofo em pesquisas empíricas.

No mesmo sentido, a "importação" das formulações do pensamento de Heidegger que resguardam similitude com a conceptualidade da geografia ou a precipitação em estudos de caso ou pesquisa empírica com o recurso destas noções extraviam o caminho que, sugere-se, permite divisar uma perspectiva de investigação passível de desenvolvimento ulterior consistente entre a geografia e a fenomenologia-hermenêutica de Heidegger, qual seja, encetar um programa de reabilitação do problema da fundamentação ontológica na Geografia, sob as diretrizes do pensamento do referido filósofo. Na medida em que, contudo, a possibilidade de se desenvolver um programa de pesquisa dessa ordem é afetado pelo modo mesmo com o qual o mesmo programa tem é obstruído, notadamente pela forma com a qual a interlocução com o filósofo está prevalemente estabelecido na disciplina, é preciso, preliminarmente, expor a natureza dessa obstrução, a fim de reservar, para um momento subsequente o encaminhamento positivo 
do referido programa, articulando os elementos referidos no parágrafo anterior.

São efetivamente poucos os estudos que disponibilizam esses elementos (Joronen, 2010; Elden, 2001; Pickles, 1985) no contexto interno da geografia. As analogias formais com as noções do pensamento do filósofo, bem como a precipitação da "aplicação" da fenomenologia de Heidegger em pesquisas empíricas deveriam ser sustadas, em favor de uma necessidade mais fundamental, a saber - fomentar o sentido de seu pensamento no âmbito de uma ciência particular, levando em conta a advertência do próprio filósofo, com a qual se conclui a presente reflexão: "A ontologia só pode contribuir indiretamente para fomentar as disciplinas positivas existentes. Ela possui, por si mesma uma finalidade autônoma, caso a questão do ser constitua o estímulo de toda busca científica, além e acima de uma simples tomada de consciência dos entes" (Heidegger, 2013, p.97, grifo nosso).

\section{Referências}

BORHEIM, Gerd. Metafísica e Finitude. São Paulo: Editora Perspectiva, 1970.

CARLOS, Ana Fani Alessandri. A condição espacial. São Paulo: Editora Contexto, 2011.

CASANOVA, Marco. Mundo e Historicidade: Leituras Fenomenológicas de Ser e Tempo. Volume 1: Existência e Mundanidade. Rio de Janeiro. Editoria Via Verita, 2017.

DAL GALLO, Priscila M. A ontologia da Geografia à luz da obra de arte: o embate Terra-Mundo em "Out of África". 2015. Dissertação. 97f. (Mestrado em geografia). Instituto de Geociências, Unicamp, 2015a.

DAL GALLO, Priscila M. ; MARANDOLA JR., Eduardo . O conceito fundamental de mundo na construção de uma ontologia da geografia. GEOUSP: espaço e tempo, v. 19, p. 551-563, 2015b.

ELDEN, Stuart. Between Marx and Heidegger: Politics, Philosophy and Lefebvre's The Production of Space. Antipode, UK, V. 36, p. 86-105. 2004a.

Continuun, 2004b.

Understanding Henri Lefebvre. Theory and the Possible. London:

. Contribution to Geography? The espace of Heigegger's Beiträge. Environment and Planning D: Society and Space, UK, V. 23, p. 819-827. 2005.

.Mapping the Present: Heidegger Foucault and the Project of a Spatial History. London: Continuun, 2001.

GALVÃO FILHO, Carlos Eduardo Pontes. Por abismos...casas...mundos...a geosofia como narrativa fenomenológica. 2016. Dissertação. 120f. (Mestrado em geografia). Instituto de Geociências, Unicamp, 2016.

GOMES, Paulo Cesar da Costa. Geografia e Modernidade. Rio de Janeiro: Bertrand Brasil, 2011.

HEIDEGGER, Martin. Ser e Tempo. 8․ ed. Petrópolis, RJ: Vozes; Bragança Paulista, SP: Editora Universitária São Francisco, 2006.

2009.

Sobre o humanismo. $3^{\circ}$. ed. Rio de Janeiro: Tempo Brasileiro 
HEMMING, Laurence P. Heidegger and Marx. A Productive Dialogue over the Language of Humanism. Evanston, Illinois. Northwestern University Press, 2013

HOLZER, Werther. A Geografia Humanista: sua trajetória 1950-1990. Londrina: Eduel, 2016.

JORONEN, Mikko. The Age of Planetary Space: On Heidegger, Being, and Metaphysics of Globalization. 2010. 227f. Tese (Doutorado em Geografia) Departamento de Geografia, Universidade de Turku, 2010.

KAHLMEYER-MERTENS, R. S. Book Review. Revista de Filosofia Unisinos. 14 (2): 169 - 174, may/aug. 2013.

KOBAYASHI, Audrey; MACKENZIE, Suzanne. (Orgs). Remaking human geography. Boston Unwin Hyman, 1989.

LEY, David; Fragmentations, coerence, and limits to theory in human geography. In: KOBAYASHI, Audrey; MACKENZIE, Suzanne. (Orgs). Remaking human geography. Boston Unwin Hyman, 1989.

MARANDOLA Jr, Eduardo. Lugar Enquanto Circunstancialidade. In: Qual o espaço do lugar?: geografia, epistemologia, fenomenologia. São Paulo: Perspectiva, 2014a.

Fenomenologia e Pós-Fenomenologia: Alternativas e projeções do fazer geográfico humanista na geografia contemporânea. Geograficidade, RJ, v.3, n.2, Inverno. 2013.

Habitar em risco: mobilidade e vulnerabilidade na experiência metropolitana. SP: Blucher, 2014b.

Heidegger e o pensamento fenomenológico em Geografia: sobre os modos geográficos de existência. Geografia, Rio Claro, v. 37, p. 81-94, jan/abr. 2012.

Humanismo e a abordagem cultural em Geografia. Geografia, Rio Claro, v. 30, n. 3, p. 393-419, set/dez. 2005.

Identidade e autenticidade dos lugares dos lugares: o pensamento de Heidegger em Place and Placelessness, de Edward Relph. Geografia, Rio Claro, v. 41, n. 01 p. 05-15, jan/abr. 2016.

Prefácio. In: DARDEL, Eric. O Homem e a Terra: natureza da realidade geográfica. São Paulo: Editora perspectiva, 2011.

MORAES, Antônio Carlos Robert. Em Busca da Ontologia do Espaço. In: MOREIRA, Ruy (Org.) Geografia: Teoria e Crítica. Rio de Janeiro: Editora Vozes, 1982.

MOREIRA, Ruy. Geografia e Práxis: a presença do espaço na teoria e na prática geográfica. São Paulo: Editora Contexto, 2012.

PICKLES, John. Phenomenology, science and geography: spatiality and the human sciences. Cambridge: Cambridge University Press, 1985.

RELPH, Edward. Rational Landscapes and Humanist Geography. New York, USA: Routledge, 1981.

REIS, Luís Carlos Tosta dos. Ontologia da Produção do espaço na Geografia: uma abordagem do tema através do diálogo entre Milton Santos e Heidegger sobre a técnica. Geografares, Vitória nํ13, p. 01-39, dez. 2012. 
. Ontologia do espaço e movimento de renovação crítica da geografia: o desafio da diferença ontológica. Geografares, Vitória, ํo 7, p. 111-122, dez. 2009.

SANTOS, Milton. Por uma Geografia Nova: Da Crítica da Geografia a uma Geografia Crítica. 6‥ ed. São Paulo: EDUSP, 2008.

SARTRE, Jean-Paul. Crítica da razão dialética. São Paulo: ED\&A editora, 2002.

SHATZK, Theorore R. Martin Heidegger: Theorist of Space. Stuttgart: Steiner, 2007.

SILVA, Armando Corrêa da. O Espaço como Ser: uma auto-avaliação crítica. In: MOREIRA, Ruy (Org). Geografia: Teoria e Crítica. Rio de Janeiro: Editora Vozes, 1982.

STROHMAYER, Ulf. The event of space Geographic allusions in the phenomenological tradition. Environment and Planning D: Society and Space, v. 16, p. 105-121. 1998. 